\title{
Utilizing the Literatures in Teaching the Research Paper
}

JOHN SWALES

University of Michigan

Teaching research English, particularly the writing of papers, to nonnative speakers (NNS) has not been given the attention it needs. Available evidence points both to the overwhelming role of English as a medium of communication in the international research literature and to the low level of NNS contributions to that literature. This article outlines and illustrates an approach to the teaching of research English (on a group rather than an individual basis) which derives from four bodies of literature: (a) the sociology of science, (b) citation analysis, (c) technical writing, and (d) English for academic purposes. It is argued that this approach gives the ESL instructor insight into research writing processes and products, increases instructor confidence, provides accessible content, and produces texts from the literatures that can be used directly in class. The discussion reviews present knowledge of the research paper; considers the issues of genre, schema, and rhetorical structure; and relates the orientation taken in this article to the current debate about "process" and "product" approaches to ESL writing.

\section{THE CASE FOR TEACHING THE RESEARCH PAPER}

Teaching the research paper to nonnative-speaker (NNS) graduate students and staff is not, in my experience, a responsibility that all university-employed ESL instructors embrace with noticeable relish and confidence. Around the world there seem to be many instructors who feel that such teaching must somehow be an arcane activity largely beyond their professional preparation and competence. For one thing, these instructors see research-paper teaching as bedeviled with uncontrollable and abstruse content and enmeshed in disciplinary cultures (Becher, 1981) or discourse communities (Herrington, 1985) of diversely alien character. And certainly, given the fissiparous tendencies within late 20th century graduate education, diversity is apparent enough (Bazerman, 1981). 
Today, Milton's "grove of academe" increasingly resembles an arboretum rather than a forestry plantation. A further typical source of disquiet lies in the perceived difficulty of handling issues of research methodology and research rhetoric at an appropriate level of sophistication. If we add to these twin apprehensions the fact that few instructors will have had any direct training in teaching the research paper (it is not discussed in either Kennedy \& Bolitho, 1984, or McDonough, 1984) and the clear sense in the field of English for academic purposes (EAP) that undergraduates comprise the priority target population, then it is easy to see why teaching the research paper has retained Cinderella status.

Even if such anxieties and demurrals are real and understandable, equally pressing are the responsibilities of those charged with providing an adequate range of ESL services in major universities and other research institutions. To start with, the rapid rise of English as the world's premier language of international communication is nowhere else as clearly demonstrated as it is in the field of research and scholarship. Within that field, the research paper, as a presented or printed document, is the standard product of the knowledge-manufacturing industry.

The annual world output of research papers (in all languages) currently runs to several million. Although undistorted figures for the proportion of papers published in English are hard to establish (but see Baldauf \& Jernudd, 1983a, and Swales, 1985a), a reasonably conservative estimate would be that at least half of these millions of papers are published in the English language, and in some disciplines considerably more than half. Furthermore, Baldauf and Jernudd (1983a) have clearly shown that, despite some predictions to the contrary, the predominance of English has been steadily increasing over the last two decades. Thus, there is every indication that English will remain the primary language of research at least for the remainder of this century. In the longer term, however, much will presumably depend on the language use patterns that emerge in the research communities of the so-called Pacific Rim (Australia, Singapore, Taiwan, China, Korea, Japan, the western seaboard of the Americas, etc.).

Overall, the role of the NNS in this Anglocentric research environment remains rather obscure. The limited available evidence (Baldauf \& Jernudd, 1983b; Swales, 1985b) indicates a relatively low level of NNS contribution to the "visible" Englishlanguage research literature, and what contributions there are emanate principally from NNSs located (with varying degrees of permanence) in anglophone environments and from the more developed nonanglophone countries of the northern hemisphere. 
Hence, once again, we see a North-South imbalance in the worldan imbalance reflected in the uncomfortable fact that numbers of able people in isolated and "off-network" places are being excluded from actively participating in international scholarship and research.

The reasons for the relative absence or invisibility of nonanglophone research, particularly from lesser developed and smaller countries, are obviously complex. The research environments are likely to be less supportive. NNS researchers need to take time out from their academic and scientific careers to develop and sustain high-level English language skills (Lewin \& Jordan, 1981). There may well be editorial bias against submissions from obscure places or from authors who are apparently NNSs. Limited library resources will probably mean that only the most prestigious journals - those with the highest rejection rates-will be subscribed to, thus curtailing knowledge of alternative outlets. Possibly there will be misconceptions about the appropriate length, style, and organization of research reporting in English.

Even if we do not know in any precise way how much of this low NNS productivity can be ascribed straightforwardly to lack of the relevant English language skills, we would be unwise, I believe, to assume that uncertainties about English language usage are of marginal or negligible importance. If that belief is correct, then those of us concerned with ESL in settings that include research cannot easily shrug off responsibilities for preparing and assisting NNSs to participate fully in English-dominated international research communities. In anglophone situations (North America, Britain, Australia, etc.), this would involve not only helping NNSs to write dissertations and so on, but also doing whatever we can to ensure that those NNSs have sufficient competence and confidence in their English-language research writing to carry on after graduation. In nonanglophone settings, we have the responsibility of providing supporting services for doctoral and other returnees and of offering specialized courses that will at least partially compensate those who have not had access to English-medium higher education.

1 therefore suggest that such a program is more than just a luxury, given the likelihood that in many parts of the world and in many fields (not excluding applied linguistics and ESL), there exists "a lost generation" of well-trained but quasi-invisible NNS scholars and researchers. And if that is so, then we face hard questions indeed about the return on the investment made by straitened Lesser Developed Countries in the overseas graduate scholarships they award to their nationals, as well as questions about the longer 
term intellectual value of fellowships, scholarships, and visitorships offered to NNSs by Western governments and other sponsoring agencies.

A final reason for taking the teaching of research English seriously lies in the widely recognized difficulty of research writing. For instance, experienced ESL professionals, doubtless like other groups of experts, rarely find it easy to write up their inquiries, investigations, and research into publishable form-a well-attested phenomenon which should convince us that those with a lesser command of the language will, other things being equal, experience even greater difficulty.

\section{APPROACHING THE RESEARCH PAPER}

The preceding discussion has tried to make a case for giving greater attention to the teaching of the research paper-for giving Cinderella at least an invitation to the ball. Even if the target group is small and suspiciously elite, it is also one at greater risk to career advancement, due to shortage of high-level English language skills, than almost any other. However, in making this recommendation, I have also tried to acknowledge that instructors may have good reasons for being wary of venturing into the territory of the research paper, partly through lack of insight into this "macrogenre" (Widdowson, 1983a) and partly through lack of role models for courses of this type.

This article's first aim is to dispel some of that reluctance by discussing a range of literatures that are concerned in very different ways with research reporting. The claim is that the diverse perspectives embodied in these literatures provide the ESL instructor with a rich background of knowledge, insight, and interpretive strategy that can serve as a solid, confidence-building orientation to this type of teaching. In addition, and perhaps more important, the article attempts to demonstrate that these literatures not only provide insight for the instructor, but also contain within them textual extracts that can be used as primary resources, that is, as actual teaching materials. The phrase "utilizing the literatures" is thus used in this dual sense. The literatures considered here are (a) the sociology of science (or knowledge), (b) citation analysis, (c) technical writing, and (d) EAP (as it pertains to research reporting). It will be noted that only the last two have anything to do with teaching and that only the last falls within the ambit of ESL.

Before considering how these four distinct research disciplines might be utilized (and there are other possible candidates such as the history of research writing and research into higher education), 
it is first necessary to clarify what is here meant by teaching the research paper. In the first place, this article concentrates on what can be done in a class setting, in particular in those "awkward" classes of 20 or more graduate students coming from a wide diversity of disciplines and possessing levels of general English proficiency varying from the good intermediate to the advanced. In other words, the article is not concerned with the one-on-one or small-group consultancy devoted to the restructuring and editing of individual and student-generated pieces of writing. This type of service is well established, noncontroversial, and of proven value. (For intriguing studies of such consultancies in operation, see Ballard, 1984, and James, 1984.) The only major problem with such consultancies is that they are hopelessly cost-ineffective, especially if more senior and expensive staff are involved. Given such time and budgetary constraints, it therefore becomes all the more necessary to see what can be done with larger groups. We need preventive medicine as well as dissertation surgery. In the second place, this article is primarily concerned with teaching the writing of the research paper, although both incidentally and by design, opportunities for developing reading skills, for textual analysis, for lexico-syntactic experimentation, and for discussion and oral presentation do occur.

\section{UTILIZING THE LITERATURES}

The Sociology of Science

In a recent paper, Myers (1985) reports on the struggles of two established biologists, Dr. Bloch and Dr. Crews, to get their papers published. For Myers, all researchers are faced with decisions about the level of claim they might wish to make. The higher the level of claim, the more likely that it will involve contradicting large bodies of the relevant literature and will challenge assumptions embodied in important ongoing research programs. On the other hand, lowlevel claims may contradict nothing but may also add very little to what is accepted and established within the given research field. Thus, high-level claims are likely to be important but risky, while low-level claims are likely to be trivial but safe.

Both of Myers's biologists consistently sought to make the highest level claim that they could persuade a particular journal to accept, but in both cases they eventually had to settle for the publication of much more limited and lower level claims than they had originally hoped for (and perhaps still hope for). The main value of Sample Text 1, which is an extract from Myers's article, lies mainly in the 
way it demonstrates that the apprentice-researcher may not be alone in having difficulty in getting a paper accepted. However, it also usefully exemplifies the publishing process and its attendant vocabulary.

1. 1) First, each author wrote a wide-ranging draft he did not submit for publication. 2) Then they wrote more limited and conventional manuscripts for submission to major interdisciplinary journals: Nature (in Dr. Bloch's case) and Science (in Dr. Crews's case). Dr. Bloch's was rejected without review, while Dr. Crews's was reviewed by two referees who split their decisions: it was also rejected. 3) Each author then revised and resubmitted the manuscript to the same journal, with a covering letter asking for reconsideration: both were reviewed and again rejected. 4) Still confident that their manuscripts were important, they resubmitted to other prestigious interdisciplinary journals, Dr. Bloch revising somewhat for Science, Dr. Crews revising drastically for Nature. This time Dr. Blochs article got an ambivalent but generally favorable review but was still rejected, while Dr. Crews's article was returned without review. 5) After these rejections by Science and Nature, both authors submitted to journals with more limited audiences that seemed more likely to accept the articles. Dr. Bloch sent a revised version to a journal recommended by one of the referees at Nature, the Journal of Molecular Evolution. It was accepted on the condition that certain changes suggested by the referees and editor were made. Dr. Crews submitted the unrevised Nature manuscript to PNAS, where the referees were generally favorable, but still recommended rejection. 6) Finally, both articles were published. Dr. Blochs manuscript was accepted in its revised form in the Journal of Molecular Evolution, where it appeared in December 1983. Dr. Crews's unrevised manuscript was accepted at Hormones and Behavior on the basis of its previous reviews, and appeared in March 1984. The revisions between each of these stages are extremely complex, ranging from massive cuts and additions to shifting of an adjective or a comma. (pp. 600-601)

Sample Text 1 is a suitable early text in a research writing course. It is rich in manuscript-related technical vocabulary and also gives rise to some useful analytic activities, such as that elicited by the following assignment:

Study Sample Text 1 and produce two boxed flow charts, one showing what happened to Dr. Blochs manuscript and the other what happened to Dr. Crews's manuscript.

The two histories related in Sample Text 1 may be atypical because both biologists were trying to edge away from the research areas in which they had established their reputations. However, these histories do at least undermine any belief that the scientist- 
researcher is necessarily less concerned with the niceties of description and explanation or with the subtleties of rhetorical persuasion than, say, the literary critic, the historian, or the political scientist. Furthermore, if we turn to the earlier stages of the composing process, the preparation of a manuscript prior to review, we can find impressive evidence that any vision we may have of the scientist-researcher working away in the lab and then retiring to a quiet place to type up quickly the experimental report according to some stereotyped format is decidedly at odds with reality.

Evidence for what really happens can be gathered from three recent book-length studies that are largely concerned with the construction of research papers. Two are case studies of important U.S. laboratories (Knorr-Cetina, 1981; Latour \& Woolgar, 1979); the third is an analysis of a controversy in biochemistry (Gilbert \& Mulkay, 1984). All three books are significant products of a relatively new school within the sociology of science in which discourse is topic rather than resource, in which text is no longer used as evidence of historical fact but as reflection of beliefs about the contextual and rhetorical organization of a research world.

Latour and Woolgar's (1979) study of the Salk Institute in California is probably the most remarkable, certainly the most controversial. Latour, a French anthropologist, comments that the strange Salk Institute tribe "spend the greatest part of the day coding, marking, altering, correcting, reading, and writing" (p. 49). The aim of all this documentary activity is not to preserve administrative records, but to make contributions to the research front in the form of published papers. This interpretation is expressed in the following striking paragraph:

2. Firstly, at the end of the day, technicians bring piles of documents from the bench space through to the office space. In a factory we might expect these to be reports of what has been processed and manufactured. For members of this laboratory, however, these documents constitute what is yet to be processed and manufactured. Secondly, secretaries post off papers from the laboratory at an average rate of one every ten days. However, far from being reports of what has been produced in a factory, members take these papers to be the product of their unusual factory. (p. 47)

Sample Text 2 is best utilized as a discussion prompt. Does the text exaggerate the reporting stage? Do the authors fail to distinguish fact and statement of fact? Does the documentary world of Latour and Woolgar conveniently ignore the substances and animals left behind as research moves from raw data to Results sections? And so on.

UTILIZING THE LITERATURES IN TEACHING THE RESEARCH PAPER 47 
For our purposes, the most relevant section of the Knorr-Cetina (1981) volume is the chapter on "The Scientist as a Literary Reasoner." Here, Knorr-Cetina presents an extensive textual study, including facsimiles and also supported by direct observation and interview, of what transpired between the first rough notes for and the final draft of one paper produced at a large governmentfinanced research center in Berkeley, CA, during 1977. The subject of the paper is the recovery of protein from potatoes, a process of some significance for the food industry.

The first significant point to emerge is that the public story as told in the drafts is a reversed, even more than revised, version of what actually took place within the confines of the laboratory. In the laboratory the realization that ferric chloride coagulation could occur without heat eventually led to the establishment of an alternative method, while in the paper, the story opens with the need to produce a better method and then offers ferric chloride coagulation as a resolution of this need. Of course, this reversal of the research dynamic is, in its context, neither deceitful nor misrepresentative, although it might be thought so if the laboratory notes themselves had been revised in this way. After all, the research paper is a genre quite different from the laboratory record and has its own quite separate conventions, its own processes of literary reasoning, and its own standards of argument. Within this genre, one powerful shaping paradigm is the problem-solution text type (Hoey, 1979).

But the story of the introduction to the paper does not end here because there are further differences between the first full version and the final version. In the first, there is a clear succession of increasingly specific paragraphs, starting with observations about the large quantities of valuable potato proteins available in the world and how these are underutilized. A description of current recovery methods follows, with considerable emphasis on their drawbacks. The introduction ends with a discussion of a major alternative coagulant (ferric chloride), which would turn the disadvantages of the current methods into advantages.

Several months and drafts later, a final version emerged after considerable discussion with and comments from colleagues, including the Director of the Institute. The straightforward and somewhat dramatic unfolding of the first version has almost entirely disappeared. The general-specific structure ("zeroing in on the solution") has been abandoned for a series of paragraphs that discuss various topics at approximately equivalent levels of detail, thus producing a more discursive and less goal-directed text. Further, many "dangerous" claims have been eliminated, and there 
has been a considerable increase in hedging. Sample Text 3 consists of the final sentences from the introduction in the first and final drafts, respectively.

3a. The aim of this work was to find an alternative precipitation method resulting in a yield comparable to that of protein recovered by means of the most commonly used acid/heat treatment method, while achieving a more acceptable quality of the PPC needed for the application 0 in human foods. (p. 157)

b. The purpose of this study was to compare the effectiveness of $\mathrm{HC1}$, $\mathrm{FeCl}$, and $\mathrm{HC} 1$ combined with heat, as precipitant of potato protein in the laboratory, as well as under pilot plant conditions, and to evaluate some compositional, nutritional and functional characteristics of the protein concentrates recovered by these three methods. (p. 165)

Sample Text 3 provides both a comparative exercise for group work and a connection to the negotiation of claims to knowledge illustrated in Sample Text 1. Its purpose is to help students see how a bold announcement of a new method has become a much tamer comparative analysis; how the early exuberance of the primary researchers has become the careful statement of a wider group; and how potential damage to the Institute's reputation, if things go awry, has been limited. (Alternative scenarios are, of course, possible: Students can be asked to guess which draft was first and which final, or they can be asked to tone down the first draft in various ways. )

In contrast to the two other books, Gilbert and Mulkay's (1984) work offers an analysis of the various ways in which a major controversy in biochemistry is described and discussed by the leading protagonists. The accounting for "the facts" seems to vary along two major dimensions. The first relates to where a particular researcher "stands" vis-a-vis the currently fashionable position. More specifically, Gilbert and Mulkay are able to show the tension between a need to recognize good work by others-however unpalatable-and a need on the researcher's behalf to protect his (or more rarely her) "investment" in time, equipment, money, effort, and kudos. The second major variation in accounting relates to public and private statement-more specifically to the difference between what is said in formal published papers and what is said in informal interviews with the two sociologists.

Thus, Gilbert and Mulkay argue that the ordered variability of research discourse can be explained by recognizing the existence of two repertoires: the empiricist and the contingent. In the former, there is no mention of authors' involvement with or commitment to 
particular analytic positions nor of their social ties with like-minded colleagues. Furthermore, experimental work is described in a laconic and conventional manner, and this description is one of impersonal procedures of universal effectiveness and applicability. "Empiricist discourse is organized in a manner which denies its character as an interpretative product and which denies that its author's actions are relevant to its content" (p. 56).

The contingent repertoire emerged in interviews in which "scientists presented their actions and beliefs as heavily dependent on speculative insights, prior intellectual commitments, personal characteristics, indescribable skills, social ties and group membership" (p. 56). Gilbert and Mulkay go on to demonstrate that an important kind of humor in the academic world depends on playing off one repertoire against the other. In addition to certain other changes, Sample Text 4 (adapted from pp. 176-177) has been converted into a matching exercise to be unscrambled by students working in pairs.

4. Lineup the equivalent statements in Columns I and II.

Column I (empiricist) What they wrote

a. It has long been known that

b. Findings of some importance

c. Correct within an order of magnitude

d. A low-intermediate group of students was chosen as especially suitable

e. Three of the six variables were subjected to detailed statistical analysis

f. Results of doubtful significance
Column II (contingent)

What they meant

1. We were already teaching them

2. The other three were really screwed up

3. I haven't bothered to look up the references

4. Work done by our group

5 . Work done by a rival group

6. Wrong

The four sample studies reviewed in this section indicate in their varying ways the strength of the genre-specific conventions that constrain and shape the research paper. In addition, they affirm that writing a research paper is neither a simple nor a trivial activity. The four textual fragments selected for in-class examination are offered as suitable samples for "consciousness-raising" sessions, even though they have been ordered so that they increasingly relate to the textual surface. The important questions that arise with regard to content choice, discipline specificity, and the value of student rhetorical 
analysis are examined in the Discussion section, where they are addressed in the full context of the literature-utilizing approach proposed here.

\section{Citation Analysis}

The second body of literature that I believe to be worth incorporating into an NNS research-paper course is citation analysis. This field extends from highly quantitative studies typically based on bibliometric data, such as citation indexes, to qualitative concerns with citing behavior as manifested in text. The former's purposes are to evaluate the research productivity and influence of countries, institutions, or individuals (Martin \& Irvine, 1984); to trace the influence of certain publications; or to map via statistical techniques the boundaries of cognitive fields (Rip \& Courtial, 1984). The qualitative end of the spectrum aims to develop adequate topologies for classifying citations (Frost, 1979; Peritz, 1983; Swales, 1986a) or to construct a defensible theory of citing (Bavelas, 1978; Cronin, 1981; Gilbert, 1977). Those adopting quantitative techniques tend to be information scientists, while those with a more contextual orientation are more typically sociologists. Historians of ideas may use both types of methodology.

In fact, very few papers in the quantitative literature are sufficiently concerned with the language variable to warrant incorporation into a course on writing a research paper. One of these few is Baldauf's (1986) paper, an adapted extract from which (PP. 220-221) appears as Sample Text 5.

5.

$$
\begin{gathered}
\text { Linguistic Constraints on Participation } \\
\text { in Psychology } \\
\text { Richard B. Baldauf, Jr. } \\
\text { James Cook University, Australia }
\end{gathered}
$$

Russell (1984), in his paper on psychology in its world context, has shown how the dominance of English as a universal language in psychology limits the potential development of psychology as an international discipline. I would like to elaborate further on this important issue using data which describe the linguistic characteristics of four cross-cultural psychology journals. The study is based on 338 articles published between 1978 and 1982 in the Journal of CrossCultural Psychology (JCCP), the International Journal of Psychology (IJP), the International Journal of Intercultural Relations (IJIR) and the Interamerican Journal of Psychology (IAJP). Three hundred and twenty seven, or 97\%, of the studies were published in English. ... 
Language of Citations

In Table 1 [not shown here] the language of the 8489 citations provided for the 338 articles is given. Ninety-seven percent of the citations were in English. While citations were found in 16 languages, an English speaker with French, German, Spanish, and Hebrew as second languages could read $99.5 \%$ of the cross-cultural psychology literature cited in these four journals. The fact that about $92.5 \%$ of the psychology literature cited in Psychological Abstracts is written in English, along with the figures given here, suggests that some crosscultural psychologists may be missing relevant research due to the language barrier. Although this failure to communicate is undoubtedly less of a problem than in the physical sciences (see Lewin, 1981), it certainly does not contribute to the advancement of cross-cultural psychology and puts a particularly difficult burden on speakers of languages other than English who want to have their work read and cited.

The Baldauf extract is a useful study-and-discussion text for a number of reasons:

1. It deals with useful terminology (cited, citations, language barrier, acronyms and their pronunciation).

2. It shows an interesting relationship between the first and second sentences. Also of interest are the use of authorial comment ("I would like ...," "this important [italics added] issue"); the narrowing from "psychology as an international discipline" to "cross-cultural psychology"; the early (contrastive?) mention of data; the use of elaborate as opposed to develop, extend, or confirm.

3. Present passive is used in the third sentence, and past passive in the fourth.

4. Lexical superordination is used: "this . . . issue" (second sentence), "this failure" (last sentence and possible variants).

5. The extract raises questions of sample size and methodology.

6. It raises the issues of why language use patterns may not contribute to the advancement of a discipline and whether anything can be done about it.

More important, the last two issues lead naturally to a class project particularly suitable for a heterogeneous group of graduate students coming from a wide variety of disciplines. For this project, each student takes an international journal from his or her field and analyzes an agreed number of recent articles in terms of the language of publication and the language(s) of the citations. The class-pooled expertise is used to identify individually unrecognized 
languages. A master table of all the findings is prepared, and then small groups discuss, draft, and redraft the emerging research paper.

Although my long-held ambition of getting the English class to research a topic, write it up in a form appropriate to a particular journal, submit the paper, and gain acceptance has yet to be realized, I still harbor hopes that such a citation analysis project can eventually be successfully completed. A project of this type has a number of advantages: (a) It develops search reading skills; (b) the quantitative nature of the investigation appeals to the scientists and engineers who often comprise the majority of the class; (c) the English language issue falls naturally within the competence of the instructor; and (d) the topic may be of direct concern and relevance to the NNS class participants.

The utilization of the qualitative citation analysis literature is not so easy to demonstrate. However, in the following activity, the class is first provided with a checklist of reasons that have been proposed for citing the work of others. They are then given the following sample text or, if appropriate, a "simpler account" of it (Widdowson, 1979).

6. Citation, ultimately, is a 'private process', ${ }^{14}$ albeit a . . . private process with a public face, but the essential subjectivity of the act of citing means that the reason why an author cites as he does must remain a matter of conjecture. We lack what Swanson calls a 'convenient and rapid method of discovering the nature of the relevance link which the citing author has established'. ${ }^{15}$ This conjectural element is worth pursuing precisely because the endproduct of the private process (the citation) acquires the status of a public commodity. Assumptions are made about the nature of this commodity, yet its real import is obscured by the secretiveness of the production process. Textual analysis of the citing paper cannot tell us why an author cites as he does, though it may suggest very plausible reasons. To quote Mulkay, 'there has been no clear demonstration of the way in which citations reflect the process of scientific influence'. ${ }^{16}$ (Cronin, 1981, pp. 16-17)

Matters can now proceed in a variety of ways. A first step may be for the students to interview each other about their citing behavior in general and in relation to specific texts they have written and brought to class. Alternatively or additionally, the instructor distributes a citation-rich introduction written by a colleague and then plays a tape of a recorded interview with the colleague designed to elicit the reasons for the individual citations. The students then select a paper written by one of their professors, make an appointment, prepare for the interview, and-armed with the 
Cronin text and, if possible, a cassette recorder-conduct the interview. The results are studied and relayed back to the group or class. The hidden agenda behind all this activity is in fact fairly obvious. The tasks provide an opportunity to demystify the process, to recognize the complexity of the motivations, to appreciate that many of the decisions made are judgment calls, and ultimately to gain a feel for this kind of text.

\section{Technical Writing}

Since this body of literature is uncomfortably large, the discussion of it here is extremely selective. As the illustrations from the two previous bodies of literature consisted of fragments of scholarly and research texts, this discussion concentrates on the subsection of the technical writing literature that consists of manuals and style guides aimed at assisting the native speaker to write acceptable research papers.

In these instructional materials, there is an interesting difference of opinion with regard to the need to include in the introduction a statement or announcement of the principal findings. This minor skirmish will have to serve as but a single example of utilizing this literature. In fact, a number of well-regarded manuals do not consider the issue at all (Michaelson, 1982; O'Connor \& Woodford, 1976). However, where it is discussed, the preponderance of advice is to include the principal findings (Calman \& Barabas, 1973; Dudley, 1977). The most assertive statement of this view is contained in the popular volume by Day, entitled How to Write and Publish a Scientific Paper (1979). Day's fourth and final rule for a good introduction comprises Sample Text 7.

7. It should state the principal results of the investigation. Do not keep the reader in suspense; let the reader follow the development of the evidence. An O'Henry surprise ending might make good literature, but it hardly fits the mold that we like to call the scientific method.

Let me expand on that last point. Many authors, especially beginning authors, make the mistake (and it is a mistake) of holding up their most important findings until late in the paper. In extreme cases, authors have sometimes omitted important findings from the Abstract, presumably in the hope of building suspense while proceeding to a well-concealed, dramatic climax. However, this is a sophomoric gambit which, among knowledgeable scientists, goes over like a double negative at a grammarians' picnic. Basically, the problem with the surprise ending is that the readers become bored and stop reading long before they get to the punch line. "Reading a 
scientific article isn't the same as reading a detective story. We want to know from the start that the butler did it." (p. 24)

On the other hand, I have traced only one manual writer-Huth (1982)-who unequivocally recommends leaving out a statement of results:

8. Some authors close the Introduction with a short statement of the research findings. This practice has been justified as a device to hold the reader's attention; it has been criticized as moving the conclusion from its logical place in the sequence of argument. One reason for keeping the conclusion at the end of the paper is that many journals now publish full summaries or abstracts on their title pages. Why give the answer twice at the beginning of the paper? (p. 53)

This contrasting pair of sample texts (7 and 8$)$ serves the research writing class in a number of ways:

1. The two texts are a useful stimulus for a discussion about individual preferences.

2. As the texts are essentially secondary sources, the next step is to ask the class to search out and examine the advice given (if any) in the primary sources of guidance in their fields (the style guides produced by associations and journals). The findings are then reported back.

3. The third step is to carry out small individual or group projects designed to validate the advice against what actually happens in the introductions to papers from the students' disciplines. (In fact, experience suggests that the majority of advice is likely to be "more honored in the breach than in the observance.")

4. Once again, there is a hidden agenda-to develop an ability to come to terms with the frailty of human advice, to gain an appreciation of the different expectations of different fields, and to further the capacity to see how information is structured in the research article.

\section{English for Academic Purposes}

The final body of literature to be utilized, that of EAP, brings the discussion closer to surface-level features and their manipulation and development. However, as several of the previous "resource" texts have dealt with introductions to research papers (i.e., Sample Texts $3,5,7$, and 8 ), the ensuing commentary is also confined to that context. For a number of reasons, this is a sensible restriction.

First, much of the debate about EAP research methodology has centered on introductions, in particular the issues of the value of 
"subject specialist informants," their selection, and their integration into a hermeneutic cycle (Huckin \& Olsen, 1984; Selinker, 1979). Second, this type of text has figured prominently in the search for the identity and boundary criteria necessary to set up textual subdivisions of a discoursal character (Bley-Vroman \& Selinker, 1984; Crookes, 1986; Swales, 1981). Third, several studies have compared the function and distribution of linguistic features across introductions and methods, results, and discussion sections. In these terms, West (1980) investigated that-nominals; Heslot (1982) voice and tense; Tarone, Dwyer, Gillette, and Icke (1981) first person pronoun use versus use of the passive; Weissberg (1984) paragraph structure; and Adams Smith (1984) the frequency of various kinds of authorial comment. Finally, some EAP research has been concerned with features of introductions themselves. Dubois (1982) was able to show that many complex noun phrases tend not to be lifted wholesale from elsewhere but are gradually built up and consolidated as the introduction proceeds. The still unresolved issue of the best way of accounting for tense variation in the reporting of previous literature has been/was/is discussed by Oster (1981), Een (1982), and Swales (1983).

There is also some evidence to suggest that short introductions in the mainstream "harder" disciplines tend to have a four- or five-part information structure. In these areas, this evidence is probably strong enough to warrant some pedagogical applications, although elsewhere this is not so at present. Crookes (1986) has demonstrated considerable variation in the social sciences, and Cooper (1985) has shown a different structure in many technical research reports in electronics.

The actual characterization of the mainstream structure may be viewed in terms of a problem-solution model. This, for instance, is the route taken by Zappen (1983); in an introduction "the research addresses the goals, current capacities, problems and criteria of evaluation that derive from and operate within that discipline" (p. 130).

An alternative model (Swales, 1986b) uses the ecological metaphor of "creating a research space. " At the outset, the writer of an introduction may need to establish that the particular area of research is of some significance. This is most commonly achieved by claiming that the area is not peripheral: Authors may claim that there is interest in it, that it is important or relevant, that it has been widely investigated, or that standard procedures have evolved. This done, the second move is to summarize selectively the relevant previous research. The rhetorical role of the third move is to show that the reported research is not complete. This is principally 
effected by indicating a gap in the previous work or by raising a question or a hypothesis. Finally, the gap is turned into the research space for the present article, or an offer is made to answer the question or test the hypothesis. And inevitably, the smaller the research space (i. e., the less evident the existence of an unfilled ecological niche in the research area), the greater the rhetorical "work" that will be necessary.

Nevertheless, it is worth noting that these two models may not be in direct competition, for we may need both kinds of metaphorical caricature to capture the development of the arduously crafted introduction sections of research papers. We may need to account for both description and persuasion, for both logical surface and egocentric subtext. Sample Text 9 provides a suitable introduction for class work. (Sentence numbers have been added.)

9 .

\section{INTRODUCTION}

[1] There are many situations where examination scripts are marked by one examiner and then re-marked by another examiner. [2] One examiner may be checking on the marking standards of the other examiner (Black, 1962), or else the marks of the two examiners may be averaged in order to attempt to produce a more reliable assessment (Wiseman, 1949; Wood and Quinn, 1976). [3] It has been suggested by Pilliner (1965) that one of the critical factors which affect the re-marking of scripts is whether or not the second examiner is aware of the marks awarded by the first examiner. [4] In fact, Pilliner suggests that if the second examiner is aware of the marks awarded by the first examiner then this invalidates the independence of the two assessments of the script. [5] Furthermore, an impression has been gained from re-marking investigations (e.g., Murphy, 1978) that more extreme differences in marking standards are revealed when previous marks and comments are removed from scripts. [6] It would seem that however much an examiner tries to ignore the judgments of a previous examiner when he is re-marking scripts, his own impression of the scripts is bound to be influenced.

[7] The aim of this investigation was to test this view by comparing the results of re-marking two sets of scripts, one set with previous marks and comments on them and the other set with these removed. (Murphy, 1979, p. 73)

The passage opens with a typical appeal to the readership underscoring the significance of the research area (compare "many situations" with a few or some). The second sentence provides illustration and support for the first one; the use of the rare progressive "may be checking" is clever in its implication that this very process may well be taking place at the time when the article is being read. The next three sentences (3-5) create a research space 
by downplaying the present state of knowledge ("It has been suggested," "Pilliner suggests," "an impression has been gained"). We find the research hypothesis in Sentence 6 and an offer to evaluate it in Sentence 7 (with again some downplaying of present knowledge by the choice of view as opposed to, say, assumption or belief.

The methodology for teaching this structure relies initially on techniques of text marking and text assembly. In text marking, an extract is marked, blocked, and labeled in various ways by the class, either individually or in pairs or small groups, sometimes in class and sometimes for preparation. The following are typical types of these student text-marking activities:

1. Insert section labels if these are missing or have been removed.

2. In the margin, draw two vertical lines at varying distances apart to show narrowing and widening of scope (see Hill, Soppelsa, \& West, 1982).

3. Block up and label/number an introduction according to some version of a model.

4. Link-with lines, blocked text, and numbers-parts of the abstract to parts of the introduction.

The next stage requires the class to produce introductions from their own fields and to see how well they fit the model. (Sets of pastel marker pens are excellent for this kind of marking up. )

In the text-assembly, "scrambled sentences," or "strip story" technique, portions of the text are placed out of order and have to be reordered correctly. In textbooks this is usually done by printing the text fragments in the wrong order. However, if circumstances permit, it is much better to have the fragments cutup and placed in envelopes because this enables the students to view and read through an experimental reassembly. As might be expected, a normal practice is to start with large fragments (i. e., sections), then move on to parts of sections (i. e., "moves") and finally to individual sentences.

Fancy variations of this technique include (a) requiring the students to locate the place where a fragment has been deliberately removed by the instructor, (b) adding extraneous fragments for identification and removal, (c) providing envelopes (or whatever) with two strip stories to disentangle and reassemble, and (d) indeed going to the malicious trouble of having a range of texts and putting not quite all the fragments in the right envelopes so that groups have to trade their surpluses for their shortages. Whatever variation is chosen, the group activity underlines the need for a multiple 
strategy in reordering: content clues, coherence and cohesion, rhetorical structure and schematic expectations, levels of lexical abstraction, and so on. And of course, if these manifold considerations are needed for successful reconstruction, does it not follow that those same considerations are needed for successful composition?

Finally, we need to recognize that the various sections of introductions provide well-motivated opportunities for undertaking language work on such specific topics as the following:

1. Opening sections: generalizations of various types

"There are many situations where..." (Sample Text 9)

"It has become a common practice for one examiner . . ." (Sample Text 9 variant)

"Recently, there has been wide interest in ..."

"For some time there has been evidence that ..."

"A full explanation for ... is not yet available."

2. Sections handling previous research

a. Choice of reporting verb (show, suggest, claim, stress, etc.)

b. Place of the cited researcher/research in the sentence (as subject, agent, in parentheses, etc. )

c. Cohesion and coherence in literature reporting "A further study that bears upon this question is ..." "Additional evidence in support of . . . is provided by ..." "Somewhat different conclusions were reached by . . ."

3. Sections indicating a gap

a. Contrastive connectors (however, nevertheless, in spite of, etc.)

b. Negative quantifiers (no, none of, few, little)

c. Verbs of negative import (restricted to, lack, neglect, limited to, fail)

d. Indirect questions "It is not yet clear whether ..."

4. Sections announcing present research

a. Demonstratives (this, the present)

b. A switch to we "We now report the interaction of ..."

c. Overt and underlying locatives "In the present paper, figures are reported which ..."

"The present paper reports figures which ..."

d. Tense and purpose

UTILIZING TIIE LITERATURES IN TEACHING TIIE RESEARCII PAPER 59 
Use of the present or the past if the noun indicates the type of inquiry (investigation, study, research, experiment, analysis, etc. )

"The aim of this investigation was to..."

"The aim of this investigation is to..."

Use of the present only if the noun indicates the type of presentation (paper, article, report, thesis, note, etc.)

"The aim of this paper is to..."

\section{DISCUSSION}

At the end of the day, the picture we have of the research paper is somewhat incomplete. However, at least the pieces we do have all seem to belong to the same jigsaw puzzle. In other words, findings of research from different traditions and undertaken for diverse reasons are on the whole supportive rather than conflicting. Four of these findings are worth summarizing:

1. The research article is a product that varies from one field to another in terms of its conventionality and standardization. In those areas of knowledge variously described as hard, exact, or physical, consensus on objectives, ground rules, and points of departure has led to textual products with a regularized microstructure and with rhetorics that follow identifiable role models. In such cases, the genre is a clear outcome of the intersections of thematic, procedural, and stylistic constraints. As is well known, this experimental role model has been jealously admired by many researchers in those sciences variously described as soft, human, or behavioral. In these areas, therefore, there has been some attempt to adopt and adapt the hard-science paradigm, as is illustrated most tellingly by the incredible increase in the size of the Publication Manual of the American Psychological Association during this century (from 6 to 208 pages). Finally, in much of the humanities, role modeling is more a matter of the influence of "intellectual schools or scholarly traditions" than of the disciplines themselves. In general, differences between papers, reviews, and chapters in books are less easily detected.

2. There are two principal corollaries of this variation. First, the more established the conventions, the more articulated the genre. Thus, on a superficial level, the research paper becomes increasingly divided into standardized divisions (introductionmethods-results-discussion or a disciplinary variant); on a less obvious level, we are more likely to find that different sections will have different rhetorical features (e.g., introductions in 
contrast to methods sections). The second corollary is that as we move toward the diffuse end of the continuum, it becomes more necessary for authors to engage in acts of persuasion that will encourage the readership to share particular visions of the research world.

3. On the other hand, there area number of phenomena that appear to be relatively constant. Research articles are rarely simple narratives of investigations but are complexly distanced reconstructions of research activities. Part of this reconstruction process derives from a need to anticipate and discountenance negative reactions to the knowledge claims being advanced. And this need in turn illuminates the long-standing (Shapin, 1984) and extensive use of hedges as rhetorical devices, both for projecting honesty, modesty, and proper caution in self-reports, as well as for diplomatically creating research space in areas heavily populated by other researchers.

4. In stylistic terms, sentence length is close to the norm for expository prose. However, the research paper is differentiated from most other expository genres by its powerfully nominal style (Smith, 1982), wherein as many as a third of the sentences may have equative be as the main verb. The lexis is becoming increasingly abstract (as indeed a diachronic study of this journal reveals), and lexical repetition and paraphrase are key devices for maintaining cohesion in introductions and discussions. The range of voice, tense, aspect, and modality is narrow, and patterns of occurrence vary significantly from section to section, particularly in harder fields. Overall, there is a perceivable interrelationship between the research paper as a peer-group intellectual object, the abstract nominal style, and the presence of authorial intrusion in contexts thought to need persuasive support or to need some revelation of the author's individual cognitive processes.

I would venture to suggest that these gleanings from diverse literatures provide a valuably broad orientation for instructors, both in terms of what they might wish to look for and how they might look for it. In addition, it is my experience that knowledge of these bodies of literature provides us with an impressive series of talking points when entering into discussions with subject-area departments. We no longer need to go naked into those conference chambers.

Furthermore, these bodies of literature seem to point us toward an approach to teaching the writing of the research paper that concentrates on making students aware of the constraints and 
opportunities created by their being situated in a genre-specific context. This is because a genre "is a rhetorical means for mediating private intentions and social exigence; it motivates by connecting the private with the public, the singular with the recurrent" (Miller, 1984, p. 163). Indeed, Miller goes on to argue that "what we learn when we learn a genre is not just a pattern of forms or even a method of achieving our own ends. We learn, more importantly, what ends we have" (p. 165). Our students then need to learn that they may create a research space for themselves, that they may "sell" their research area, and that they may uncouple the chronological order of research action from the spatial order of its description and justification.

In the introduction, I put forward some geopolitical arguments for giving a higher priority to the writing of the research paper as well as an administrative argument for not abandoning the hope of teaching some of the high-level skills involved in fairly large classes. In so doing, I hope not to have given the impression that students' individual interests, anxieties, and relative strengths and weaknesses are to be ignored. I fully accept-and would indeed be the first to advocate- that both instructor and student time need to be devoted to individual projects and consultancies; all the same, it seems equally important to see what can be done with groups-and often heterogeneous ones at that.

The ensuing problems with appropriate content have perhaps been only partially solved. The first three sample texts represent investigative studies of the process of research writing; the fourth provides some light relief; the fifth deals usefully with the language issue, and the sixth with motivations for citing; Sample Texts 7 and 8 contrast prescription and description; and Sample Text 9 deals with the process of educational assessment-a topic of universal interest and debate.

Over the last few years, these kinds of extracts have served me well enough, but there may be better ones. The tasks associated with the later sample texts (5-8) have required data from individual disciplines to be gathered, consolidated, and then cooperatively written up. Extracts of the type displayed in this article would, of course, be only a part of any research-paper writing course. I have not discussed, for instance, the individual and more open-ended writing tasks, which are based on topics of personal research interest and intercalated with the more general activities. Nor have I referred to the "reformulation" element (Cohen, 1983), which plays an increasingly important role.

The literature-utilization approach is premised on the early need to make students, whether native or nonnative speakers, more 
sensitive to the rhetorical structures that more or less recur in specific genres. There is little new in this, as the following statements demonstrate:

In-depth comprehension of a written academic text depends on the reader's ability to perceive the notional blocs that comprise a text and the hierarchical relationships that conceptually align them. (Blanton, 1984, p. 43)

A knowledge of the rhetorical divisions of an experimental-research paper and the function of those divisions within the paper greatly enhances ESL student reading and writing skills. (Hill et al., 1982, p. 338)

It seems, then, that formal schemata need to be activated and developed, not so much as rigid templates against which all texts are forced to fit, but rather as caricatures which self-evidently simplify and distort certain features in an attempt to capture general identity. However, the significance of schemata is much better established in the area of ESL reading comprehension (e.g., Carrell, 1983; Stanley, 1984) than it is for ESL writing. Apart from Johns (in press), there seem to be relatively few investigations at present that show the value of appropriate schematic and rhetorical perceptions in the ESL composing process. Thus, the rhetorical-sensitivity element in the approach proposed here requires further empirical validation.

Several of the topics raised in the latter half of this discussion pertain to current debate on "process" and "product" in teaching ESL writing. Oversimplifying somewhat, it appears that the majority of ESL writing teachers would today accept the following three propositions: Writing is a recursive process; writing is a heuristic undertaking; and writing is very difficult without the vocabulary to write with (Raimes, 1983). Beyond this, however, it is possible to detect differences in emphasis.

On the one hand, there are those who emphasize the internal aspects of composing (Spack, 1984; Woods, 1984; Zamel, 1983) and thus stress prewriting and invention strategies, the training of students to develop awareness of their own writing processes, the value of drafting and redrafting, the selection of topics of individual interest, the relaxation of time constraints, and so on. On the other hand, there are those who give greater attention to external determinants of composing (Horowitz, 1986; Widdowson, 1983a, $1983 b)$ and thus emphasize less the cognitive relationship between the writer and the writer's internal world and more the relationship between the writer, the writing environment, and the intended readership. The main activities here focus on the need to clarify 
purpose and on ways of anticipating and countenancing the reactions of the intended audience.

I would like to argue that the literature-utilizing approach to research-paper writing offers, within its admittedly specialized context, one way of usefully incorporating both emphases. Many activities within this approach require students to relate in various ways to reports of what actually happens in the composing of research papers, to reflect upon levels of knowledge claim, and to introspect on reasons for citing the work of others. Concomitantly, students are asked to analyze textual products representative of the genre and take part in activities that use such authentic texts as caricature-type models. What binds the process and product activities together is an underlying commitment to search out reality, so that prescriptive and presumptive elements in both the process and product areas can be detached from our growing understanding of how things are in the real world of research reporting.

\section{THE AUTHOR}

John Swales is the Acting Director of the English Language Institute and Visiting Professor of Linguistics at the University of Michigan. He has worked in ESP for many years and in various places. He is co-editor of the ESP Journal and the author of Episodes in ESP (Pergamon, 1985).

\section{REFERENCES}

Adams Smith, D.E. (1984). Medical discourse: Aspects of author's comment. ESP Journal, 3, 25-36.

Baldauf, R.B. (1986). Linguistic constraints on participation in psychology. American Psychologist, 41, 220-224.

Baldauf, R. B., \& Jemudd, B.H. (1983a). Language of publications as a variable in scientific communication. Australian Reuiew of Applied Linguistics, 6, 97-108.

Baldauf, R. B., \& Jernudd, B.H. ( 1983b). Language use patterns in the fisheries periodical literature. Scientometrics, 5, 245-255.

Ballard, B. (1984). Improving student writing: An integrated approach to cultural adjustment. In R. Williams, J. Swales, \& J. Kirkman (Eds.), Common ground: Shared interests in ESP and communication studies (pp. 43-45). Oxford: Pergamon. 
Bavelas, ].B. (1978). The social psychology of citations. Canadian Psychological Review, 19, 158-163.

Bazerman, C. (1981). What written knowledge does: Three examples of academic discourse. Philosophy of the Social Sciences, 11, 361-382.

Becher, T. (1981). Towards a definition of disciplinary cultures. Studies in Higher Education, 6, 109-122.

Blanton, L.L. (1984). Using a hierarchical model to teach academic reading to advanced ESL students: How to make a long story short. ESP Journal, 3, 37-46.

Bley-Vroman, R., \& Selinker, L. (1984). Research design in rhetorical/ grammatical studies: A proposed optimal research strategy. English for Specific Purposes, 82-83, 1-4; 84, 1-6.

Calman, J., \& Barabas, A. (1973). Writing medical papers: A practical guide. London: Heinemann.

Carrell, P.L. (1983). Some issues in studying the role of schemata, or background knowledge in second language comprehension. Reading in a Foreign Language, 1, 81-92.

Cohen, A.D. (1983). Reformulating compositions. TESOL Newsletter, $17(6), 1,4-5$.

Cooper, C. (1985). Aspects of article introductions in IEEE publications. Unpublished master's thesis, University of Aston, Birmingham, England.

Cronin, B. (1981). The need for a theory of citing. Journal of Documentation, 37, 16-24.

Crookes, G. (1986). Towards a validated analysis of scientific text structure. Applied Linguistics, 7, 57-70.

Day, R.A. (1979). How to write and publish a scientific paper. Philadelphia: ISI Press.

Dubois, B.L. (1982). The construction of noun phrases in biomedical journal articles. In J. Hoedt, L. Lundquist, H. Picht, \& J. Quistgaard (Eds.), Pragmatics and LSP (pp. 49-67). Copenhagen: School of Economics.

Dudley, H. (1977). The presentation of original work in medicine and biology. Edinburgh: Churchill Livingstone.

Een, J.A. (1982). Tense usage in reporting research in geotechnical writing, Working Papers in ESL, 2, 72-91. Minneapolis: University of Minnesota.

Frost, C.O. (1979). The use of citations in literary research: A preliminary classification of citation functions. Library Quarterly, 49, 399-414.

Gilbert, G.N. (1977). Referencing as persuasion. Social Studies of Science, 7, 113-122.

Gilbert, G. N., \& Mulkay, M. (1984). Opening Pandora's box: A sociological analysis of scientists' discourse. Cambridge: Cambridge University Press.

Herrington, A.J. (1985). Writing in academic settings: $A$ study of the contexts for writing in two college chemical engineering courses. Research in the Teaching of English, 19, 331-361.

UTILIZING THE LITERATURES IN TEACHING THE RESEARCH PAPER 65 
Heslot, J. (1982). Tense and other indexical markers in the typology of scientific texts in English. In J. Hoedt, L. Lundquist, H. Picht, \& J. Quistgaard (Eds.), Pragmatics and LSP (pp. 83-103). Copenhagen: School of Economics.

Hill, S. S., Soppelsa, B. F., \& West, G.K. (1982). Teaching ESL students to read and write experimental-research papers. TESOL Quarterly, 16, 333-347.

Hoey, M. (1979). Signaling in discourse (ELR Monograph 6). Birmingham, England: Birmingham University.

Horowitz, D.M. (1986). Process, not product: Less than meets the eye. TESOL Quarterly, 20, 141-144.

Huckin, T., \& Olsen, L. (1984). On the use of informants in LSP discourse analysis. In A. Pugh \& J. Ulijn (Eds. ), Reading for professional purposes (pp. 120-129). London: Heinemann.

Huth, E.J. (1982). How to write and publish papers in the medical sciences. Philadelphia: ISI Press.

Kennedy, C., \& Bolitho, R. (1984). English for specific purposes. London: Macmillan.

Knorr-Cetina, K.D. (1981). The manufacture of knowledge. Oxford: Pergamon.

James, K. (1984). The writing of theses by speakers of English as a foreign language: The results of a case study. In R. Williams, J. Swales, \& J. Kirkman (Eds.), Common ground: Shared interests in ESP and communication studies (pp. 99-113). Oxford: Pergamon.

Johns, A.M. (in press). The ESL student and the revision process: Some insights from schema theory. The Basic Writing Teacher.

Latour, B., \& Woolgar, S. (1979). Laboratory life: The social construction of scientific facts. Beverly Hills, CA: Sage.

Lewin, R. A., \& Jordan, D.K. (1981). The predominance of English and the potential use of Esperanto for abstracts of scientific articles. In M. Kageyama, K. Nakamura, T. Oshima, \&T. Uchida, (Eds.), Science and scientists (pp. 433-441). Tokyo: Japan Scientific Societies Press.

Martin, B. R., \& Irvine, J. (1984). CERN: Past performance and future prospects-I. Research Policy, 13, 183-210.

McDonough, J. (1984). ESP in perspective. London: Collins.

Michelson, H.B. (1982). How to write and publish engineering papers and reports. Philadelphia: ISI Press,

Miller, C.R. (1984). Genre as social action. Quarterly Journal of Speech, 70, 151-167.

Murphy, R.J.L. (1979). Removing the marks from examination scripts before re-marking them: Does it make any difference? British Journal of Educational Psychology, 49, 73-78.

Myers, G. (1985). Texts as knowledge claims: The social construction of two biology articles, Social Studies of Science, 15, 593-630.

O'Connor, M., \& Woodford, F.P. (1976). Writing scientific papers in English. Amsterdam: North-Holland. 
Oster, S. (1981). The use of tenses in reporting past literature. In L. Selinker, E. Tarone, \& V. Hanzeli (Eds.), English for academic and technical purposes ( $p p$. 76-90). Rowley, MA: Newbury House.

Peritz, B.C. (1983). A classification of citation roles for the social sciences and related fields. Scientometrics, 5, 303-312.

Raimes, A. (1983). Tradition and revolution in ESL teaching. TESOL Quarterly, 17 17, 535-552.

Rip, A., \& Courtial, J.P. (1984). Co-word maps of biotechnology: An example of cognitive scientometrics. Scientometrics, 6, 381-400.

Selinker, L. (1979). On the use of informants in discourse analysis and language for specialized purposes. International Review of Applied Linguistics, 17, 189-215.

Shapin, S. (1984). Pump and circumstance: Robert Boyle's literary technology. Social Studies of Science, 14, 481-520.

Smith, R.N. (1982). A statistical syntactic study of four English genres. Unpublished doctoral dissertation, University of Michigan, Ann Arbor.

Spack, R. (1984). Invention strategies and the ESL college composition student. TESOL Quarterly, 18, 649-670.

Stanley, R.M. (1984). The recognition of microstructure: A pilot study. Reading in a Foreign Language, 2, 156-168.

Swales, J. (1981). Aspects of article introductions. Birmingham, England: University of Aston.

Swales, J. (1983). Developing materials for writing scholarly introductions. In R. Jordan (Ed.), Case studies in ELT (pp. 188-200). London: Collins.

Swales, J. (1985a). English as the international language of research. RELC Journal, 16 (1), 1-7.

Swales, J. (1985b). English language papers and authors' first language: Preliminary explorations. Scientometrics, 8, 91-101.

Swales, J. (1986a). Citation analysis and discourse analysis. Applied Linguistics, 7, 39-56.

Swales, J. (1986b, March). The experimental research article: An applied genre analysis. Paper presented at the Conference on College Composition and Communication, New Orleans.

Tarone, E., Dwyer, S., Gillette, S., \& Icke, V. (1981). On the use of the passive in two astrophysics journal papers. ESP .Journal, 1, 123-140.

Weissberg, R.C. (1984). Given and new: Paragraph development models from scientific English. TESOL Quartedy, 18, 485-500.

West, G.K. (1980). That-nominal constructions in traditional rhetorical divisions of scientific research papers. TESOL Quarterly, 14, 483-489.

Widdowson, H.G. (1979). Explorations in applied linguistics. Oxford: Oxford University Press.

Widdowson, H.G. (1983a). Learning purpose and language use. Oxford: Oxford University Press.

Widdowson, H.G. (1983b). New starts and different kinds of failure. In A. Freedman, I. Pringle, \& J. Yalden (Eds.), Learning to write: First language/second language (pp. 34-47). Harlow, England: Longman. 
Woods, D. (1984). A process orientation in ESL writing. In L. Young (Ed.), Carleton papers in applied language studies I (pp. 101-138). Ottawa: Carleton University.

Zamel, V. (1983). The composing processes of advanced ESL students: Six case studies. TESOL Quarterly, 17, 165-187.

Zappen, J.P. (1983). A rhetoric for research in sciences and technologies. In P.V. Anderson, R.J. Brockman, \& C.R. Miller (Eds.), New essays in technical and scientific communication (pp. 123-138). Farmingdale, NY: Baywood. 